\title{
PROTECCION Y AYUDA MUTUA \\ EN LAS REDES FAMILIARES. TENDENCIAS Y RETOS ACTUALES
}

\author{
José Luis Izquieta Etulain \\ Universidad de Valladolid
}

Entre las tareas y funciones que tradicionalmente ha venido ejerciendo la familia, una de las más importantes ha sido la de protección, cuidado y atención de las personas con algún tipo de carencia o problema. Esta dimensión aparece asociada a la práctica de la reciprocidad y se halla presente en la propia naturaleza de los vínculos familiares.

La crisis y los cambios que en la actualidad experimentan estos vínculos, unidos a la propia revisión que los antropólogos y sociólogos realizan de sus enfoques y perspectiva, parecen poner en cuestión no sólo la presencia de esta función, sino incluso la propia existencia de estas redes de protección.

Sin embargo, junto a esta constante nos encontramos, paradójicamente, con otras que muestran la continuidad y, en cierto modo, la revalorización de las formas de ayuda y protección familiar. Para gran parte de las personas que viven en nuestras sociedades avanzadas, las relaciones familiares continúan siendo preponderantes. Al mismo tiempo, la crisis del Estado de Bienestar y las nuevas iniciativas sociales parecen llevar al potenciamiento y revitalización de las redes informales de atención social.

Atendiendo a estos hechos, y conscientes de su importancia, pretendemos estudiar los rasgos y las constantes que definen y caracterizan a este tipo de protección. Para ello nos ocuparemos de tres aspectos. Delimitaremos en primer lugar la naturaleza, la extensión y variabilidad que presenta la protección y la ayuda entre parientes. En segundo lugar analizaremos su forma y dinámica 
actual. Partiendo de los cambios experimentados por nuestra sociedad y por la propia familia trataremos de explicar cómo se plantea y expresa, en qué medida las nuevas estrategias familiares condicionan y mediatizan su realización. Finalmente, expondremos algunos de los problemas y retos a los que se enfrenta este tipo de protección, así como sus posibles alternativas.

\section{AYUDA Y PROTECCION EN LAS REDES FAMILIARES: NATURALEZA Y DIMENSIONES}

La importancia que para los individuos y la sociedad tiene la protección familiar no se corresponde con la preocupación ni con el interés que se ha prestado al análisis de su naturaleza, de sus fundamentos y constantes. El estudio de la ayuda familiar ocupa un lugar marginal en las investigaciones sociales. Tal vez su obviedad y el hecho de diluirse en otras actividades explican no sólo el olvido, sino también la ambigüedad conceptual con que se la entiende. Los autores que se ocupan de esta dimensión se refieren a ella de un modo indirecto. Frecuentemente, la limitan al horizonte de la solidaridad intergeneracional (Orizo, 1991: 63-74). En algunos casos la entienden como una forma de reciprocidad (Sahlins, 1977: 210-229). Habitualmente se alude a ella como una de las funciones básicas de la familia (Sussman-Burchinal, 1980: 95-113). En la mayor parte de los casos se da por hecho su existencia, sin explicar las causas y factores que justifican su presencia en todas las sociedades y su continuidad y vigencia en nuestro propio entorno sociocultural.

Partiendo de esta constatación pretendemos adentrarnos en el análisis de esta práctica intentando identificar su naturaleza, su expresión y sus constantes y variaciones. Más concretamente, nos interesa delimitar: 1) los fundamentos en que se asienta; 2) los ámbitos en los que se hace presente; 3) sus peculiaridades y diferencias.

Para enfrentarnos a estas cuestiones nos situamos en una perspectiva amplia. Entendemos a la familia: 1) como grupo doméstico, es decir, como grupo residencial, con funciones reproductivas básicas (mantenimiento de sus miembros y cuidado de los dependientes); 2) como núcleo procreativo, grupo de personas unidas por relaciones sociales primarias que tienen su origen en los mecanismos de procreación, en los que se establecen relaciones básicas, que no necesariamente suponen la existencia de matrimonio y la corresidencia de quienes lo integran (González Echevarría, 1994: 95).

Desde esta noción se constata que la protección constituye una parte esencial de la familia. Ahora bien, ¿cuál es la razón, el soporte en el que se sustenta o del que deriva esta práctica?

La respuesta a este interrogante admite diferentes posibilidades. Una de las opciones posibles es la de identificar la propia estructura o configuración de los vínculos familiares. Atendiendo a la naturaleza de estas relaciones se observa que dichas relaciones surgen a través de la procreación (vínculos de sangre) 
y habitualmente, aunque no necesariamente, mediante el matrimonio (vínculos de afinidad). Dentro de ellas se combinan tres tipos de relación: de filiación, entre padres e hijos; de afinidad, entre esposos; de consanguinidad, entre hermanos (Radcliffe-Brown, 1986: 66). En cada caso aparecen diferentes competencias, derechos y obligaciones.

Las relaciones de filiación suponen un tipo de vínculo que implica distintas tareas: 1) concebir y/o engendrar; 2) criar, alimentar, proteger; 3) instruir y educar; 4) responsabilizarse y ser valedor ante la sociedad; 5) otorgar un estatuto y unos derechos, asignar un estatuto social.

Conducen, al mismo tiempo, a una serie de relaciones personales, íntimas, heredadas o presentes desde el nacimiento, por medio de las cuales las personas se unen a un conjunto de descendientes y ascendientes con los que inevitablemente mantienen determinadas obligaciones.

Dentro de este tipo de relaciones sobresale, por su intensidad, la relación madre-hijo, unidad social elemental e irreductible. Mediante este vínculo primario, el niño "aprende" a mantener relaciones con los otros, aprende a confiar en sí mismo y en su propia capacidad, a sentirse seguro. La protección y el cuidado aparecen en esta relación como algo esencial. Los vínculos entre hermanos, aunque no suponen la existencia de una relación contractual, permiten desarrollar igualmente una confianza y unas obligaciones muy profundas.

En segundo lugar, en todas las sociedades, el matrimonio da pie a la creación de relaciones tanto entre grupos como entre individuos, produce una reordenación de las relaciones entre personas y, en consecuencia, de los derechos y deberes que son elementos de tales relaciones. Su justificación se encuentra, principalmente, en las funciones y servicios que presta (sexuales, domésticos, económicos) y en los derechos que implica (residencia, apropiación de las capacidades de procreación, ayuda y cooperación), no sólo entre los individuos, sino también entre los grupos de parentesco a los que pertenecen (Godelier, 1991: 38-43). La vía de la alianza abre, por tanto, una diversidad de espacios para ejercer y recibir ayuda. Las posibilidades se multiplican al estrechar lazos con otro grupo en el que se encuentra con otras personas ajenas a su propio grupo hacia las cuales se ve obligado y de las que también tiene la potencialidad de recibir apoyo, especialmente de padres y hermanos del cónyuge.

Desde esta aproximación tenemos una primera referencia a la naturaleza de la protección familiar, constatamos su presencia como un aspecto esencial de los lazos familiares. Pero la expresión y dinámica de la protección familiar viene determinada por una razón más inmediata y directa. La base que impulsa o fuerza la protección familiar se encuentra en la norma de la reciprocidad.

Su presencia se confirma al considerar la articulación de estas relaciones. Si atendemos al modo en que se plantean constatamos que el vínculo que une a los parientes supone el afecto, pero implica también obligaciones y deberes. Es 
decir, los vínculos familiares tienen un soporte afectivo que impulsa y conduce a la preocupación, cuidado y atención de aquellas personas a las que se considera emocionalmente próximas; pero, además, crean un conjunto de obligaciones morales, más o menos rígidas. El pertenecer a una red de parientes conlleva, además de los lazos afectivos, una serie de derechos y deberes específicos y una serie de actitudes bien definidas. Los parientes tienen el derecho de recibir ayuda y la obligación de otorgarla. Los derechos de unos son obligaciones de los otros, y viceversa.

En este sentido, se constata que la vida familiar implica una dependencia mutua y se realiza en el ordenamiento equivalente de los servicios recíprocos. Los parientes, al aportar ayuda, están convencidos de que a la larga el intercambio de bienes y servicios se equilibrará; confían en que aquellos a quienes han ayudado les devolverán la ayuda cuando ellos la necesiten; piensan, igualmente, que si no ayudan a los parientes que les ayudan deberán sufrir ciertas consecuencias.

La lógica que preside este tipo de intercambio viene marcada por la norma moral de la reciprocidad, en la que se impone la obligación de dar, recibir y devolver (Mauss, 1971: 254). Se trata de una norma transcultural en la que se plantean dos exigencias mínimas relacionadas entre sí: 1) la gente debe ayudar a quien le ha ayudado, y 2) la gente no debe perjudicar a quien le ha ayudado. A juicio de Gouldner, esta norma no es menos universal ni menos importante que el tabú del incesto, aunque, análogamente, sus versiones concretas variarán con el tiempo y el espacio (Gouldner, 1979: 232, 245).

El horizonte en el que se plantea esta norma es más amplio que el de las relaciones familiares, pero, sin duda, tiene en ellas su principal exponente y expresión. A lo largo de su vida, los parientes realizan toda una serie de intercambios guiados por esa norma. Entre los parientes existe y se desarrolla una adhesión personalizada hacia los que les han ayudado en el pasado. Dada una experiencia de cumplimiento con los requisitos de la norma, desarrollan sentimientos orientados hacia el pasado, tales como la lealtad y la gratitud. Al mismo tiempo, les sensibiliza con respecto al futuro. Aquellos a quienes han ayudado en el pasado tienen, a su vez, la obligación de ayudarles en el futuro.

Ahora bien, al valorar la protección familiar no debemos olvidar que muy frecuentemente los parientes, además de guiarse por el principio de la ayuda equilibrada, se prestan apoyo sin esperar o contemplar la devolución de lo dado. Los vínculos familiares reflejan, en muchas circunstancias, una conducta «altruista» en la que se conceden bienes y servicios desinteresadamente. La evidencia más clara la tenemos en la relación madre-hijo, donde funciona intensamente el denominado «altruismo duro» (Wilson, 1980: 220).

Algunos autores (sociobiólogos) explican este comportamiento recurriendo a la herencia genética: dado que los parientes comparten genes, en la medida en que se reproduce un pariente se reproduce uno mismo; por eso la ayuda que se presta a los parientes redunda en uno mismo, le beneficia directamente (Wilson, 1980: 99; Mellotti, 1981: 411-418). 
Sin embargo, al considerar la protección familiar no debemos fijarnos únicamente en su dimensión biológica, pues las relaciones familiares, como parte de la cultura, son relaciones sociales, no biológicas. Aunque se hable de consanguíneos, todos sabemos que un hijo adoptado no es un pariente de sangre y que nuestro padre lo es con independencia de que biológicamente pudiera serlo.

Más allá de esta observación, lo importante es constatar que en la protección familiar subyace una actitud más amplia que la mera reciprocidad. Los parientes se apoyan y protegen no sólo sobre la base de que han recibido ayuda en el pasado o la pueden obtener en el futuro, sino, también y además, movidos por sus respectivas necesidades y problemas, urgidos, al mismo tiempo, por la gratificación de cumplir con lo que se considera un deber. Al igual que la norma de la reciprocidad, se trata de una actitud que trasciende el horizonte de las relaciones familiares, pero es en ellas donde más claramente se manifiesta.

Los rasgos apuntados, al mismo tiempo que nos permiten entender el soporte en el que se asienta la protección familiar, nos descubren sus diferencias con otras formas de protección social. De lo indicado se desprende que la protección familiar difiere de la ayuda que se obtiene por la vía de la redistribución. En este caso, los bienes y servicios se concentran en una persona o institución (Estado), desde la que fluyen hacia la comunidad y la sociedad. Se distingue también de la protección que aporta el mercado. Aquí los bienes y servicios circulan sobre la base de la oferta y la demanda, sin generar relaciones similares y duraderas.

Conocida la naturaleza de la protección familiar, nos interesa también delimitar los ámbitos a los que llega, su contenido y dimensiones. En principio, puede afirmarse que la familia cubre y atiende, aunque no en exclusividad, la mayor parte de las necesidades que se plantean a los individuos. Se extiende a las necesidades básicas (relacionadas con el nivel de supervivencia) y a las metanecesidades o necesidades superiores (referidas al desarrollo) (Maslow, 1982). Se ocupa, en definitiva, de las necesidades físicas (sustento, cuidado en la enfermedad...), de las necesidades sociales (demandas de relación, comunicación, afecto...) y de las culturales (necesidades de identidad y sentido). La evidencia de esta amplitud se refleja en distintos hechos: frecuentemente, las propiedades y el trabajo se logran a través de los vínculos de filiación y alianza. El grupo de parientes resuelve también las demandas de seguridad, pertenencia, estima; aporta estabilidad emocional; proporciona igualmente una identidad temporal y espacial, un sentimiento de pertenencia; funciona como un sistema de identificación: «por la historia familiar se sabe quién se es y de dónde se viene» (Segalen, 1992: 91).

La complejidad de tareas y de matices que expresa la protección familiar explica que, en principio, no existan diferencias de género en cuanto a su ejecución o realización. Sin embargo, algunas dimensiones de la protección familiar se asocian frecuentemente a las mujeres. Parece que, debido a su papel en 
la reproducción, se asume implícitamente que las mujeres poseen determinadas capacidades y habilidades para cuidar. Desde una edad temprana se espera que las niñas contribuyan a asistir a otros. Al convertirse en "pequeñas auxiliares de sus madres» interiorizan el papel asistencial que afecta al modo en que se relacionan con otras personas, a sus logros educativos y a su personalidad general como adultos (Chodorow, 1984). Por eso, el cuidado de los demás es un componente básico en la construcción social del género. La comparación intercultural muestra, no obstante, que no hay nada natural que haga a las mujeres más capaces para el cuidado. «Es la vinculación de las mujeres a la familia la que determina su rol de cuidadoras y no su naturaleza especial como mujeres» (Comas, 1995: 131). Por otro lado, tal como hemos visto, la protección tiene una gama plural de espacios y dimensiones que no pueden atribuirse únicamente a las mujeres. Existen espacios en los que el varón-padre tiene un papel notable (Bell, 1980: 137).

Definidas algunas de las constantes de la protección familiar, hay que precisar que su expresión y realización admite múltiples diferencias y matices: 1) El contenido y la forma de la protección familiar dependen, en gran medida, de la estructura y configuración seguidas por el grupo familiar. 2) La protección familiar afecta a todos los miembros de la familia, pero las circunstancias y condiciones personales determinan variaciones sustanciales, tanto en el dar como en el recibir. Cada etapa del ciclo vital presenta necesidades cuya satisfacción exige mayor o menor presencia de la familia. La ayuda fluye en varias direcciones según las etapas del ciclo vital. 3) Se observan igualmente diferencias según la distancia genealógica, la mayor o menor proximidad física entre los miembros de la familia, sus propias necesidades y recursos, la clase social, la existencia o ausencia de otras formas de protección... En definitiva, el ritmo, el contenido y la dirección en el fluir de los intercambios, donaciones y contraprestaciones, aunque constantes, son variables y relativos.

Por otro lado, el reconocimiento de la importancia y centralidad de la protección familiar no debe hacernos olvidar que, aunque se trata de una práctica obligatoria, no siempre se cumple o realiza. Los vínculos familiares se hallan sujetos a crisis y cambios y no siempre funcionan equilibrada y correctamente. La escasez, la indigencia o incapacidad pueden ser motivos para su inviabilidad. En otros casos puede ser el propio olvido o desinterés, pues, como bien se sabe: «observar que una sociedad tiene un sistema de moralidad y de obligaciones no significa decir que todos lo obedezcan» (Sahlins, 1977: 223).

En consecuencia, al analizar la protección familiar no sólo deben evitarse falsas idealizaciones, sino que debe considerarse y entenderse dentro del sistema de relaciones familiares del que forma parte y en el propio contexto en el que se plantean y realizan esos mismos sistemas. Sólo desde ahí es posible identificar, definir y establecer su alcance, su contenido y sus límites.

Partiendo de estas premisas vamos a detenernos en el análisis de esta dimensión, tal como se expresa en nuestra sociedad, tratando de aportar datos y pruebas sobre su dinámica y realización. 


\section{LAS REDES DE PROTECCION EN LA FAMILIA ACTUAL. CRISIS Y NUEVAS FORMAS DE PROTECCION}

El contexto en el que actualmente se realizan las relaciones familiares se caracteriza por distintos procesos que inciden directamente en su estructura y configuración, así como en la propia expresión de la reciprocidad.

Destacan, por su trascendencia y consecuencias, la dinámica demográfica, con la reducción de la natalidad y el envejecimiento de la población; la crisis y las nuevas tendencias de la economía, con sus efectos en el trabajo y en las relaciones sociales; los nuevos valores y pautas de conducta, que llevan a priorizar las opciones individuales y a la relativización de los vínculos. Los efectos de estos cambios sobre la familia son amplios: inciden sobre los roles, actitudes y comportamientos de la mujer (Durán, 1988; Garrido, 1993); afectan a la propia estructura, composición, contenido y valoración de los vínculos familiares; provocan la aparición de nuevos modos y modelos de relación.

Junto al tipo de familia propio de la sociedad industrial emergen nuevas formas de convivencia, cada una de las cuales posee su propia lógica interna de adaptación al sistema. La familia nuclear coexiste con las familias monoparentales y unipersonales. Cada vez es mayor el número de niños que pasa una parte de su infancia bajo el cuidado de un solo progenitor, generalmente la madre. Aumentan igualmente los núcleos formados por solitarios: personas ancianas (viudos y viudas), pero también separados o divorciados jóvenes que optan por vivir solos. La opción de permanecer soltero parece cada vez más atractiva para muchos individuos (Durán, 1988; Lamourère, 1988).

Por otro lado, la dinámica matrimonial aparece asociada a nuevos modos de entender y plantear las relaciones familiares. El acto de casarse pierde significado e importancia como rito regulador de las relaciones entre parejas. Matrimonio y unión libre ya no son incompatibles. El matrimonio a prueba parece una práctica razonable y la unión libre es tolerada y admitida. La cohabitación, el divorcio, los nacimientos fuera del matrimonio han dejado de ser desviaciones y son integrados en el proceso de relaciones familiares.

Todo ello refleja un nuevo rostro o una nueva expresión de la vida familiar, provocando la coexistencia de, al menos, tres tipos: las familias de primeros matrimonios, que son las nucleares típicas; las familias monoparentales, y las familias de los casados en segundas y posteriores nupcias. Los datos y las evidencias empíricas de todo ello son numerosos y han sido valorados por distintos analistas (Alberdi, Flaquer e Iglesias de Ussel, 1994; Del Campo, 1991; Flaquer y Solere, 1990; Garrido y Gil Calvo, 1993; Iglesias de Ussel, 1994; Solsona y Treviño, 1990).

¿Qué influjo tienen estas nuevas formas de entender y realizar los vínculos familiares sobre la ayuda y protección familiar? ¿Cuál es la proyección de estos nuevos modelos y concepciones en las redes familiares?

La respuesta admite diversas interpretaciones. Para algunos autores, las consecuencias y el resultado de esta nueva dinámica es la progresiva desmem- 
bración y disolución de los lazos de parentesco y, consiguientemente, de los vínculos de reciprocidad familiar. El continuado descenso del tamaño medio de los hogares, el crecimiento de los hogares unipersonales y de los no integrados por un núcleo familiar y la presencia de la monoparentalidad, asociada a la soltería, conducen a una etapa de transición que lleva desde una «sociedad de familias» a una «sociedad de individuos», lo que significa el desvanecimiento y el propio final de la familia (Requena, 1994: 250-251; Lamo de Espinosa, 1983; 1995: 51): «Es muy posible que nuestra cultura se esté enfrentando a un reto singular, tal vez inédito: el carácter prescindible para un número creciente de individuos de la institución familiar... Las condiciones modernas de vida aflojan los nexos entre parientes hasta el punto que en muchas ocasiones pierden su sentido relacional, si es que no terminan pura y simplemente por desaparecer. Las agrupaciones de parientes son sólo el recuerdo de un tiempo cada vez más lejano" (Requena, 1992: 25, 36).

Si las redes familiares tienden a disolverse, si nuestra sociedad relativiza y afloja los nexos entre parientes, quiere decirse que las obligaciones y derechos de protección en dichas redes tenderán inevitablemente a desaparecer.

Ahora bien, los hechos y constantes que caracterizan a la familia actual, ¿Conducen inexorablemente a esta situación? ¿Estamos realmente dentro de un proceso de desintegración de los vínculos familiares y de las redes de parentesco? Y, en caso afirmativo, ¿la desaparición de estos vínculos implicaría la propia eliminación de las redes de ayuda y protección familiar?

Las ideas sobre la desmembración y progresiva pérdida de importancia de las redes familiares no son nuevas. Los cambios que la industrialización y urbanización introducen en la vida social dieron pie a que se insistiera en la ruptura y pérdida de importancia de los grupos primarios (Tönnies, Simmel). Al mismo tiempo, las transformaciones que estos mismos fenómenos imponen a las redes familiares llevaron a que algunos sociólogos pensaran en la progresiva reducción de sus funciones y en la aparición de otras formas de organización, de ayuda y protección (Parsons y Bales, 1955).

Sin embargo, pronto se constató que, aunque la teoría revelaba el aislamiento y la movilidad social, los hallazgos de los estudios empíricos descubrían la vigencia de un sistema de familia extensa, que existía y funcionaba estrechamente integrada en una red de relaciones y de asistencia recíproca, según líneas bilaterales de parentesco de varias generaciones (Sussman y Burchinal, 1980: 95113; Turner, Adams y Bell, 1980: 116-141; Bott, 1990).

En la actualidad sucede algo parecido. Los signos que revelan la vitalidad de las redes familiares son diversos, pero abundantes. La evidencia de esta continuidad la obtenemos tanto desde una consideración amplia de la dinámica seguida por los vínculos sociales en nuestra sociedad como desde un ámbito más concreto, el de las nuevas necesidades y problemas planteados hoy a distintos grupos y colectivos de nuestra sociedad.

En el primer caso, se constata que los cambios producidos recientemente no disuelven los lazos sociales, sino que, por el contrario, los favorecen o 
impulsan. La tendencia a la privacidad y el individualismo imperante «no han extinguido la necesidad elemental que todo individuo tiene de calor y espontaneidad en su relación con otros. No han hecho desaparecer el deseo de seguridad y estabilidad de la afirmación emocional de la propia persona a través de los demás, ni su contrapartida, la necesidad de convivir con otras personas con las que se está a gusto» (Elias, 1990: 235). La modernidad impulsa el refugio en la vida privada, pero las solidaridades primarias no desaparecen, sino que cobran fuerza y mantienen su vitalidad.

Tal como revelan distintas encuestas, la familia aparece como el principal referente de encuentro, afecto y comunicación, y se mantiene como una de las instituciones de mayor estima y reconocimiento. Así, para la mitad de los norteamericanos, "el principal objetivo de la vida es estar felizmente casado" (Del Campo, 1991: 26). En nuestro país, dentro de la jerarquía de aspectos que se consideran importantes en la vida, el primero de ellos es la familia. El 83 por 100 de los españoles la considera muy importante para su vida (Orizo, 1991: 41-42). Por otro lado, el porcentaje de personas que en España viven desvinculadas de las redes familiares no supera el 4 por 100, pudiendo afirmarse «con rotundidad que la convivencia con parientes por consanguinidad o afinidad constituye la forma más corriente de residencia» (Flaquer, 1990: 510).

Esta realidad pasa desapercibida a algunos sociólogos, tal vez porque «al observar las curvas de divorcio, nupcialidad y fecundidad, deducen la conmoción del modelo tradicional de matrimonio y de la familia sin percatarse de que en nuestra época existen distintas formas de plantear las relaciones de pareja» (Segalen y Zonabend, 1988: 525-526). No advierten tampoco que la familia es una red de relaciones humanas en la que se distinguen relaciones básicas o nucleares y relaciones secundarias, que sobreviven incluso cuando varía su forma de expresión.

Más allá de esta constatación puede afirmarse igualmente que la familia, a pesar de los cambios experimentados en su contenido y en su forma, continúa desempeñando, aunque no exclusivamente, gran parte de sus funciones tradicionales. Conserva su función económica y reproductora, funciona como sistema de identificación, sigue siendo un medio privilegiado para las relaciones y, de un modo especial, mantiene su función asistencial y protectora. Todo ello explica su alto índice de aceptación y estima social.

La continuidad de estas dimensiones se descubre tanto en aquellas sociedades que carecen de un nivel satisfactorio de seguridad social, es decir, sociedades que no tienen la red protectora del Estado, como en las que la poseen. En las primeras, los lazos familiares continúan siendo la mejor defensa y garantía de supervivencia (Lomnitz, 1984). En las segundas, aunque el Estado tiene un papel central en la protección, su crisis y estancamiento, asociado a la emergencia de nuevas necesidades, parecen impulsar un reforzamiento de los vínculos familiares.

Este hecho se refleja hoy de múltiples maneras. Así, la pérdida del empleo o las dificultades para conseguirlo convierten a las redes familiares en una pla- 
taforma de seguridad económica y social, en el mecanismo socioeconómico que suple la falta de otro tipo de seguridad o protección (Requena, 1991; Segalen, 1992: 87). Los datos recogidos en distintos estudios revelan sobradamente la importancia de las redes familiares para acceder al mundo del trabajo. En Francia, un tercio de jóvenes que encuentran empleo lo hacen gracias a sus relaciones familiares (Gokalp, 1981: 70). En algunos municipios del entorno industrial de Barcelona, el 70 por 100 de los jóvenes accede al empleo por vía familiar (Masjoan, Casal y Planas, 1990).

A pesar de los cambios en los sistemas de herencia y transmisión del patrimonio, la asistencia (préstamo, regalo) de padres a hijos sigue igualmente vigente (Willmott, 1987). Las encuestas revelan que la ayuda de los padres se prolonga a lo largo de todo el ciclo de la vida familiar. El 40 por 100 de los franceses reconoce que el matrimonio es una ocasión de regalos y ayudas en dinero (Roussel, 1976: 49, 62). Un 76 por 100 de la población adulta española sigue pensando que el deber de los padres es procurar lo mejor para sus hijos, aun a costa de su propio bienestar (Orizo, 1991: 228).

El apoyo que prestan los padres a los hijos no se reduce únicamente al suministro de dinero y bienes, sino que consiste también en ayuda de promoción, con lo que, además de conservar el nivel de vida y hacer frente a problemas económicos, se busca la mejora del status (Segalen, 1992: 87).

Los servicios recíprocos entre miembros de la familia son igualmente constantes. La solidaridad intergeneracional se revela como uno de los rasgos más importantes de las nuevas familias. El cuidado de los niños mientras la madre trabaja sigue estando en manos de algún miembro de la red familiar, predominantemente algunos de los abuelos. En Suecia, las guarderías se encargan únicamente del 20 por 100 de los niños en edad escolar (Gaunt, 1988), mientras que en Francia no llega al 8 por 100 (Gokalp-David, 1982).

La familia aparece también como un recurso ante otro tipo de necesidades no referidas a la posesión de bienes o a la obtención de una posición en la vida, sino orientadas a lograr una "satisfacción íntima" (Weber). La dinámica de nuestra sociedad produce un tipo de necesidades (Inglehart, 1990) que no son satisfechas desde los ámbitos institucionales y son, en cierta forma, cubiertas desde la familia. En concreto, las demandas de sentido, afecto y comunicación no son transformables en unidades monetarias y tienen que ver con un campo de bienes relacionales que no pueden ser satisfechos desde el mercado ni desde la protección institucional o pública, pues habitualmente en este ámbito los servicios y la propia ayuda se ofrecen por personas que desempeñan su competencia desde una institución en la que han sido elegidos sobre la base de su cualificación técnica y plantean un tipo de vinculación con los demandantes de ayuda impersonal (sin afecto ni entusiasmo) en la que la esfera de su competencia se halla definida desde una organización gobernada por los valores del universalismo, logro, especificidad y neutralidad afectiva, esto es, los polos opuestos a los valores que rigen en las relaciones familiares. 
En estos casos la familia se presenta como un espacio de «solidaridad difusa y duradera», un lugar donde se le acepta a uno incondicionalmente. El amor que une a la pareja, la solidaridad intrafamiliar y la solidaridad entre los hogares y las generaciones sigue siendo, para la mayor parte de las personas, su soporte y fuente de estabilidad.

Todo este conjunto de expresiones se manifiesta con más intensidad en aquellas personas que tienen algún tipo de disfuncionalidad o problema (niños, jóvenes, ancianos, inmigrantes, enfermos, minusválidos...). A muchos jóvenes, la precariedad, la falta de expectativas de trabajo, les obliga a depender de sus padres. Tienden a abandonar el hogar para estudiar, pero regresan rápidamente y recurren a los padres para obtener apoyo económico y emocional. El 70 por 100 de los jóvenes españoles entre 18 y 29 años vive con sus padres. Sólo un 15 por 100 vive con personas que no son de su familia (CIRES, 1993; Alberdi, Flaquer e Iglesias de Ussel, 1994: 19).

Los ancianos habitualmente tienen en la familia, tal como muestran distintas encuestas, su principal referente afectivo y el ámbito más importante de comunicación y contacto (Bazo, 1990). Siguen viviendo, en la medida de sus posibilidades, en el hogar y buscan la proximidad y el contacto continuado con los hijos, hermanos, familiares. La mitad de los ancianos suecos tienen contactos semanales con parientes próximos y tienen, al menos, un hijo que vive a una distancia inferior a quince kilómetros de su casa (Gaunt, 1988). En Francia, más del 75 por 100 de ancianos habita a menos de veinte kilómetros (Roussel, 1976). Un 80 por 100 de la población española piensa que, con independencia de las cualidades y defectos de los padres, se debe siempre amarlos y respetarlos (Orizo, 1991: 228).

Por otro lado, aunque se constata que los ancianos prefieren vivir independientes, en su propio hogar, se observa también que según aumentan en edad y ven limitarse su autonomía, buscan y reciben el cuidado del grupo familiar, siendo la familia el principal receptor y protector (Alberdi, 1995: 313).

Las contradicciones económicas, sociales y culturales que genera el desplazamiento a otro entorno social son resueltas, en el caso de los inmigrantes, por la vía de las relaciones familiares, que aparecen como estrategia adaptativa y de supervivencia (Andizian, 1987; Buechler, 1987; Comas y Pujadas, 1991: 3356). Su vida está, además, muy condicionada por los vínculos que siguen manteniendo con su familia de origen. El inmigrado se siente obligado a compartir sus bienes con sus familiares, enviando dinero a su casa o ahorrando con la intención de traer consigo a su familia. Por ejemplo, el 90 por 100 de las trabajadoras filipinas empleadas de hogar que trabajan en Madrid envía, como media, el 60 por 100 de su sueldo mensual a sus familiares (Giménez, 1993: 74).

En el caso de las personas que tienen algún tipo de minusvalía, aunque existen instituciones que se encargan de su cuidado y protección, es igualmente la familia la que, en última instancia, asume un papel central en su atención. La familia tiene también un protagonismo decisivo en el cuidado de los enfermos. En España, la proporción de enfermos y discapacitados que son atendi- 
dos por y en la familia alcanza el 76 por 100 (Iglesias de Ussel, 1994: 484-485; Durán, 1988). En algunos casos, como el de los ancianos enfermos, la cifra sube hasta el 90 por 100 (CIS, 1989).

El reconocimiento de estos hechos exige, no obstante, alguna matización. En primer lugar, no es fácil medir la extensión, la frecuencia y duración de estas redes de apoyo. Dada la dinámica de nuestra sociedad, admite grados y diferencias, tanto en la forma como en su intensidad: se expanden o contraen en función de las etapas por las que atraviesa el individuo a lo largo de su vida. Son intensas durante la infancia, se limitan en la adolescencia y edad adulta. Tras el matrimonio y el nacimiento de los hijos vuelven a incrementarse, y lo mismo sucede en la ancianidad (Bott, 1990: 199-200). La movilidad y la distancia geográfica condicionan la intensidad y la frecuencia de los intercambios, pero no son un obstáculo, ni la bloquean, ni disminuyen la percepción de los parientes como algo importante. Se observan, asimismo, diferencias significativas según las clases sociales. Parece que son más frecuentes e intensos en la clase trabajadora. En las clases medias es frecuente que tengan más peso los vínculos de amistad (Adams, 1980: 126-132; Bott, 1990: 157; Iglesias de Ussel, 1994: 482-483).

No obstante, más allá de los matices y peculiaridades, parece difícil negar la vigencia y revalorización de las redes de protección familiar. De lo apuntado hasta aquí se desprende que la familia sigue ejerciendo un papel de mediación entre el individuo y la sociedad, contribuye a paliar los choques de las transformaciones económicas y sociales, constituye un soporte psicológico y afectivo para los individuos, les sirve de refugio y sostén; sigue siendo, en definitiva, un ámbito privilegiado de relación, de sociabilidad, de comunicación y de ayuda material.

\section{RETOS DE LA PROTECCION FAMILIAR EN LA SOCIEDAD DEL BIENESTAR}

Esta constatación no debe hacernos olvidar, sin embargo, que estos vínculos se plantean en una sociedad sometida a procesos de cambio y se ven, asimismo, mediatizados por tensiones y presiones que, a veces, dificultan o hacen inviable su existencia. Por eso, aunque resulte paradójico, la dinámica de nuestra sociedad, en muchos casos, favorece e impulsa, según vimos, las relaciones entre los grupos de parientes, pero en otros las debilita y contrae.

Las condiciones y las causas por las que esto se produce son dispares. Así, si atendemos a los cambios demográficos, se constata que tanto la disminución de la natalidad como el envejecimiento de la población pueden convertirse en un problema para el ejercicio de la protección. La caída de la fecundidad por debajo del nivel de reemplazo generacional, tal como sucede en la mayor parte de los países occidentales; el incremento de familias sin hijos o con un solo hijo conducen a la contracción de la familia y reducen inevitablemente las 
posibilidades de los intercambios entre padres e hijos y entre hermanos. Se limita, en definitiva, el número de miembros en la unidad familiar y con ello las condiciones y miembros para el cuidado de otros.

Al mismo tiempo, el alargamiento de la vida hace que muchas personas lleguen a una edad avanzada en un estado físico y psíquico de cierto deterioro, lo que exige constantes atenciones y ayudas. Los costes materiales y psicológicos del cuidado desbordan en muchos casos la capacidad de los hijos y dejan a las personas mayores en una situación de indefensión por la carga que supone su cuidado. La situación se agrava, además, por la progresiva reducción del número de miembros y la multiplicidad de actividades que éstos asumen.

El envejecimiento constituye, sin duda, un problema para la sociedad, que debe hacer frente a gastos y ayudas extraordinarios, pero lo es especialmente para los miembros del grupo familiar que deben cuidar y atender a los ancianos. Las estadísticas no pueden dar una idea precisa de los costes que implica este tipo de cuidados; no obstante, en un estudio realizado sobre personas que en el seno de la familia se dedicaban al cuidado de ancianos, el 22 por 100 constataba que su salud se resentía y reconocía, además, que los problemas de su salud "habían sido causados o habían empeorado como consecuencia de tener que cuidar de las personas ancianas» (Charlesworth, Wilkin y Durie, 1984: 7).

Las constantes que definen la marcha de nuestra economía se convierten también para algunas familias en un problema añadido. La recesión económica potencia, a veces, el apoyo mutuo en el seno de la familia, pero frecuentemente incrementa las dificultades al reducir sus ingresos. La pérdida del trabajo o su carencia ponen en serios aprietos a muchas familias que no encuentran la vía o la forma de apoyar a sus miembros. Esto es especialmente acuciante en aquellas familias en las que el paro afecta a la mayor parte de los miembros activos. En nuestro país, por ejemplo, esta realidad se da en un 17 por 100 de hogares (Alberdi, 1995: 308).

Desde otra perspectiva, se constata igualmente que la tendencia al consumo y a la posesión de bienes reduce la capacidad de ayuda y apoyo material, al limitar la disponibilidad de las personas. Esto se ve favorecido por el talante individualista y hedonista que caracteriza al modo de vida imperante en nuestra sociedad (Bell, 1989). Los deseos de autonomía y bienestar llevan a las personas a reclamar para sí la independencia y a huir de los compromisos y las exigencias que implican, a veces, la atención de determinadas personas (enfermos, ancianos, deficientes...). El despliegue de la afectividad aparece como un rasgo de las nuevas familias, pero junto a ella se potencia y desarrolla la búsqueda de la propia realización, crece el impulso de desarrollo individual, que, en muchos casos, se opone a las exigencias implícitas en las tareas del cuidado, asistencia y preocupación por los otros. Se plantea, en definitiva, una contradicción entre el sentimiento y la obligación de ayudar y el interés personal o la urgencia de satisfacer demandas individuales.

Al mismo tiempo, muchos ciudadanos piensan que, en la medida en que el Estado capta recursos para destinarlos a la protección, es el responsable prime- 
ro y último de las personas dependientes y delegan, por tanto, en él la responsabilidad de su atención. La propia dinámica de la protección por la vía de Seguros Sociales hace que, en el caso de los ancianos, al disponer de pensiones, se dé una cierta despreocupación de los familiares; a no ser que sea ése el motivo que lleva a preocuparse de ellos, porque dependen, precisamente, de su pensión para sobrevivir o incrementar los ingresos.

El protagonismo que adquieren las nuevas tecnologías tiene sus efectos en la familia a través de su aplicación en las nuevas modalidades de reproducción, generalizadas hoy en nuestra sociedad. Su utilización introduce nuevas condiciones en las relaciones de parentesco, ya que diluyen la procreación, alteran y modifican las relaciones interpersonales y dan pie a una nueva dinámica de las relaciones de paternidad y maternidad. Todo ello repercute inevitablemente en las exigencias, derechos y obligaciones e impulsos de ayuda exigidos en los grupos de parientes.

Por otro lado, la nueva posición y los nuevos papeles asumidos hoy por la mujer dentro de la familia y en la sociedad producen una nueva situación en la realización de la protección, pues a la desvalorización que tradicionalmente han tenido las tareas del hogar se unen los costes que suponen el cuidado y la atención de determinadas personas (ancianos, enfermos...), haciendo no sólo costosa, sino indeseable dicha tarea.

Actualmente, la mujer sigue ejerciendo un papel central en la asistencia y atención. Incluso en Suecia, en donde el 80 por 100 de las mujeres trabaja fuera de casa y en donde existe una mayor igualdad entre los sexos, las mujeres siguen siendo la fuente principal de la asistencia (Johnson, 1990: 108). En la mayoría de las unidades familiares de España el cuidado de enfermos, ancianos, incapacitados y niños recae sobre ellas en proporciones, a veces, seis veces superiores a cualquier otro miembro de la familia (Durán, 1988: 87). La progresiva inserción de la mujer en el mercado laboral hace, por ello, cada vez más costosa y difícil su tarea de asistencia y cuidado de los demás, pues supone ampliar ilimitadamente su jornada de trabajo. Con lo que inevitablemente se impone una nueva forma de entender los roles vinculados a la asistencia y cuidado familiar, al mismo tiempo que se exige un apoyo y atención desde las instituciones públicas a los costes que esta tarea supone para la familia.

A todo ello se unen la movilidad geográfica, los cambios de residencia y la distancia física que hoy se hacen patentes en muchas personas. Aunque no siempre son un obstáculo para mantener relaciones, sí que en muchos momentos constituyen un límite para recibir y ofrecer ayuda. ¿Cómo hacer frente al cuidado y atención de los enfermos cuando los parientes viven distantes? ¿Cómo podemos reclamar la ayuda familiar en situaciones en las que se requiere su presencia si ésta vive alejada físicamente?

Si enfocamos el análisis desde la propia dinámica sufrida por la familia y el matrimonio en las últimas décadas, nos encontramos ante nuevos retos y dificultades. Así, el hecho de que casarse, tener hijos y mantener el matrimonio sea ahora una cuestión opcional, y no algo que se da por sentado, crea una 
nueva atmósfera más tolerante, pero convierte esas mismas uniones en algo frágil y vulnerable, con lo que el matrimonio y la familia pueden fracasar en la tarea de proporcionar "una solidaridad extensa y resistente» y una "aceptación incondicional» al no tener un soporte estable (Bellah, 1989: 149).

La explicación no resulta difícil, pues la ausencia de vínculo jurídico ofrece la posibilidad de concluir la relación en cualquier momento. El hecho de vivir juntos en una situación no legalizada da la ilusión de una salida en caso de cambios imprevistos que hagan más deseables otros planes de vida o el emparejamiento con otras personas. "Ninguna obligación debería impedir la separación. La vida en común puede ofrecer gratificaciones sexuales, apoyo emotivo, cooperación o ayuda en la satisfacción de distintas necesidades, pero nadie se debería sentir obligado por los intereses del otro miembro de la pareja, si ya no lo encuentra atractivo" (Cseh-Szombathy, 1990: 473). En definitiva, parece que la provisionalidad e inestabilidad del matrimonio pueden debilitar los lazos y hacen precarios y frágiles los compromisos y exigencias de la reciprocidad.

En estos casos, la reciprocidad no tiene por qué ir más allá de lo que dure el contacto o la relación y queda en gran medida reducida a ese espacio de tiempo. No tiene, por tanto, más soporte que el que establezca el afecto o la ley para obligar a padres con hijos o a los esposos entre sí. La red de parentesco queda aquí también limitada a los vínculos de amistad, dada la ausencia de un rito que sancione dicha unión, con lo que la obligación y la amplitud de esa relación se reducen básicamente a las que aparecen en este otro tipo de grupo.

Al mismo tiempo, el divorcio y el nuevo matrimonio de personas con descendencia plantean la convivencia en un mismo hogar de personas procedentes de distintos grupos en los que la relación resulta, en principio, más endeble y menos consistente: "No es demasiado aventurado conjeturar que la familia encontrará cada vez más dificultades para convertirse en un foco permanente de identidad personal. ¿Con quién o quiénes se identificará ese importante contingente de niños al que le será imposible convivir con alguno de sus padres?» (Requena, 1992: 45).

Algo semejante puede ocurrir en el caso de las familias monoparentales, donde el aislamiento y la debilidad de los vínculos pone en situación de precariedad e indefensión a las personas que se hallan en ese estado. Algunos de los grupos que configuran la nueva exclusión se hallan formados precisamente por las personas que participan en este tipo de familias encabezadas frecuentemente por mujeres. Un solo dato referido a nuestro país ilustra esta realidad. La frecuencia de hogares compuestos por una mujer y sus hijos es cuatro veces mayor que la de hogares compuestos por un padre y sus hijos (Iglesias de Ussel, 1988: 17).

El incremento de la soltería, con la pérdida de vínculos o la existencia de condiciones que no los facilitan, se convierte también, a la larga, en una amenaza a la estabilidad y seguridad personal, pues dadas las condiciones de nuestra sociedad es difícil disponer de recursos, salvo los que aporta el Estado o en algún caso la amistad, para hacer frente a las precariedades que puedan surgir. 
Estas situaciones descubren algunos de los límites y retos a los que se enfrenta hoy la reciprocidad familiar y revelan que la familia actual no constituye en todos los momentos el mejor soporte, el medio más eficaz y seguro de reciprocidad y apoyo. Con frecuencia, los vínculos familiares son débiles, las redes de reciprocidad familiar no existen o no son suficientes para cubrir las demandas y carencias que tienen los individuos.

Por eso, frente a los que pretenden potenciar el papel de las redes informales de atención social y buscan un mayor protagonismo de la familia en las tareas de protección, con la consiguiente reducción del papel del Estado, hay que advertir que esta medida no parece ser, en todas las situaciones, la mejor solución, pues el retroceso o reducción de las competencias del Estado en la prevención y atención de las necesidades y carencias puede suponer, a la larga, el incremento y la agudización para muchas personas de sus carencias y problemas.

Los retos y límites que en la actualidad se le plantean a la protección familiar reclaman, por tanto, un papel subsidiario del Estado en la protección social, ya que éste no sólo puede cubrir los vacíos y los ámbitos a los que no llega la reciprocidad familiar, sino que dispone de medios que sirven para reforzar y mantener los vínculos y la protección que se ejerce desde el hogar. $\mathrm{Su}$ situación de privilegio le permite planificar y prevenir los ámbitos de protección. Desde sus órganos y con sus recursos tiene la posibilidad de establecer prioridades y puede garantizar los derechos de acceso y asegurar la utilización y cobertura de múltiples servicios (Offe, 1990: 289-291; Johnson, 1990).

Ahora bien, la reivindicación del Estado no significa aceptar su presencia en la protección de idéntica forma a como se dio en el pasado. El modelo clásico se apoyaba en el reconocimiento de un solo tipo de unidad familiar, en una política natalista y en el papel de la mujer en el hogar (Esping-Andersen, 1993). Las nuevas estructuras familiares, los nuevos modelos de matrimonio y familia, las nuevas demandas, las nuevas condiciones económicas, sociales y culturales, reclaman un nuevo papel y una nueva forma de presencia. Por eso, de la misma forma que en la reciprocidad familiar se ha dado una reorientación y una modificación en su contenido y expresión, la protección pública debe también adaptarse a las nuevas condiciones y asumir los nuevos retos de la sociedad. Esto requiere no sólo una revisión y reformulación de sus fundamentos y orientaciones, sino también, y más explícitamente, un nuevo planteamiento de la política de protección y atención a la familia.

Familia y Estado se encuentran inmersos en una dinámica que les exige reorientar sus tareas y competencias atendiendo a las nuevas exigencias que imponen la sociedad y los individuos. Ambos se encuentran inmersos en un proceso dialéctico que les obliga a tenerse mutuamente en cuenta. Sólo desde estas premisas y en estas condiciones será posible dar respuesta y afrontar los problemas, demandas y necesidades que actualmente plantea la realización y el logro del bienestar individual y social. 


\section{BIBLIOGRAFIA}

AdAms, B. N. (1980): «La importancia social del parentesco», en M. Anderson (ed.), Sociología de la familia, México, Fondo de Cultura Económica, pp. 120-134.

Alberdi, I. (1995): Informe sobre la situación de la familia en España, Madrid, Ministerio de Asuntos Sociales.

Alberdi, I.; Flaquer, Ll., e Iglesias de Ussel, J. (1984): Parejas y matrimonios, Madrid, Ministerio de Asuntos Sociales.

ANDIZIAN, S., y otros (1987): Vivir entre dos culturas. La situación sociocultural de los trabajadores migrantes y sus familias, Barcelona, Serbal/Unesco.

Bazo, M. ${ }^{a}$ T. (1990): La sociedad anciana, Madrid, Centro de Investigaciones Sociológicas/ Siglo XXI.

BELL, D. (1988): Las contradicciones culturales del capitalismo, Alianza.

BELL, W., y BOAT, M. D. (1957): «Urban neighbourhoods and informal social relations», American Journal of Sociology, 62: 391-398.

Bellah, R. N. (1989): Hábitos del corazón, Madrid, Madrid, Alianza.

BотT, E. (1990): Familia y red social, Madrid, Taurus.

Buechler, H. C., y Buechler, J. N. (eds.) (1987): Migrants in Europe. The Role of Family Labor and Politics, Nueva York, Greenwood Press.

CAMPO, Salustiano del (1991): La "nueva» familia española, Madrid, Eudema.

Chappell, N. (1983): «Informal supporte among the elderly», Research on Aging, 5: 77-99.

Charlesworth, A.; Wilkin, D., y Durie, A. (1984): Carers and Services: A Comparison of Men and Women Caring for Dependent Elderly People, Manchester.

CHODOROW, R. (1984): El ejercicio de la maternidad, Barcelona, Gedisa.

CIRES (1993): La realidad social en España, Barcelona, Ediciones B.

CIS (1989): Encuesta sobre problemas y necesidades sociales, Estudio núm. 1789.

COMAS, D. (1995): Trabajo, género, cultura, Barcelona, Icaria.

Comas, D., y Pujadas, J. J. (1991): «Familias migrantes: Reproducción de la identidad y del sentimiento de pertenencia", Papers, 36: 33-56.

Csen-Szombathy (1990): "Modelo de la interrelación entre la macrosociedad y la familia", Revista Internacional de Ciencias Sociales, 126: 465-475.

DurÁN, M.a Angeles (1988a): «Hogares y familias: dos conceptos en busca de definición», en Las familias monoparentales, Madrid, Ministerio de Asuntos Sociales, pp. 11-22.

- (1988b): De puertas adentro, Madrid, Instituto de la Mujer.

Elias, N. (1990): La sociedad de los individuos, Barcelona, Península.

Esping-Andersen, G. (1993): Los tres mundos del Estado de Bienestar, Valencia, Alfons el Magnànim.

FLAQUER, Ll. (1991): “¿Hogares sin familia o familia sin hogar?: un análisis sociológico de las familias de hecho en España", Papers, 36: 57-78.

- (1993): «La familia española: cambio y perspectivas», en S. Giner (ed.), España. Sociedad y politica, Madrid, Espasa-Calpe, pp. 509-550.

Flaquer, Ll., y Solere, J. (1990): Permanencia y cambio en la familia española, Madrid, Centro de Investigaciones Sociológicas.

GARRIDO, L. (1993): Las dos biografias de la mujer en España, Madrid, Instituto de la Mujer.

Garrido, L., y Gil Calvo, E. (eds.) (1993): Estrategias familiares, Madrid, Alianza.

GaunT, L. y D. (1988): "El modelo Escandinavo", en Historia de la Familia, tomo 2, Madrid, Alianza, pp. 483-508.

Godelier, M. (1991): «Incesto, parentesco y poder», Historia y Crítica, 1: 33-55.

GoKalP, C. (1981): Quand vient l'âge des choix, París, PUF.

Gokalp, C., y David, M. G. (1982): «La garde des jeunes enfants», Population et sociétés, 161.

GonZÁlez Echevarría, A. (1994): Teorías del Parentesco, Madrid, Eudema.

Gouldner, A. (1973): La sociología actual: renovación y critica, Madrid, Alianza, pp. 214-244.

Griego, M. (1987): Keeping in the Family. Social Network and Employment Chance, Londres, Tavistock Publications. 
Harris, C. C. (1986): Familia y sociedad industrial, Barcelona, Península.

Iglesias de Ussel, J. (1988): Las familias monoparentales, Madrid, Ministerio de Asuntos Sociales.

- (1994): "Familia», en V Informe Sociológico sobre la situación social en España, Madrid, FOESSA, pp. 415-548.

INGLEHART, R. (1990): El cambio cultural en las sociedades industriales avanzadas, Madrid, CIS.

Johnson, N. (1990): El Estado de Bienestar en transición. La teoría y la práctica del pluralismo de bienestar, Madrid, Ministerio de Trabajo.

Lamo de Espinosa, E. (1983): «¿Tiene futuro la familia?», El Pais, 13 de febrero, pp. 10-11.

- (1995): «¿Nuevas formas de familia?», Claves, 50: 50-55.

LAMOURère, O. (1988): Los que vivimos solos. La soledad ya no es lo que era, Barcelona, Paidós.

LOMnitz, L. (1984): Cómo sobreviven los marginados, México, Siglo XXI.

MASJOAN, J.; CASAL, J., y Planas, J. (1990): La inserción social y laboral de los jóvenes, Barcelona, ICE-UAB.

MASLOW (1982): La amplitud potencial de la naturaleza humana, México, Trillas.

MAuss, M. (1971): Sociología y antropología, Madrid, Tecnos.

Melotti, U. (1981): El hombre entre la naturaleza y la Historia, Barcelona, Península.

Offe, C. (1990): Contradicciones del Estado de Bienestar, Madrid, Alianza.

Orizo, F. A. (1991): Los nuevos valores de los españoles, Madrid, Fundación Santa María.

Parsons, T., y Bales, R. F. (1955): Family, Socialization and Interaction Process, Nueva York, The Free Press.

RADCLIFFE-BRown, A. R. (1986): Estructura y función en la sociedad primitiva, Barcelona, Península.

Requena, F. (1991): Redes sociales y mercado de trabajo, Madrid, Centro de Investigaciones Sociológicas.

Requena, M. (1992): «El eclipse de la razón doméstica», en V. Verdú, Nuevos amores, nuevas familias, Barcelona, Tusquets.

Requena, M., y Díez de REVEnga (1993): "Formas de familia en la España contemporánea», en L. Garrido y E. Gil Calvo, Estrategias familiares, Madrid, Alianza, pp. 249-270.

RodrígueZ, J. A. (1994): Envejecimiento y Familia, Madrid, Centro de Investigaciones Sociológicas.

RousSel, L. (1980): «La crise de la famille», La Recherche, 111: 544-553.

- (1989): La famille incertaine, París, Odile Jacob.

SAhlins, M. (1977): La economía de la Edad de Piedra, Madrid, Akal.

SEgALEN, M. (1992): Antropología histórica de la familia, Madrid, Taurus.

Segalen, M., y Zonabend, F. (1992): «Familias en Francia», en Historia de la Familia, tomo 2, Madrid, Alianza, pp. 509-540.

Solsona, M., y Treviño, R. (1990): Estructuras familiares en España, Madrid, Instituto de la Mujer.

Sussman, M. B., y Burchinal, L. G. (1980): «La red familiar del parentesco en la sociedad urbana industrial de los Estados Unidos", en M. Anderson (ed.), Sociología de la familia, México, Fondo de Cultura Económica, pp. 95-113.

Turner, C.; Adams, C., y Bell, C. (1980): «La importancia social del parentesco», en M. Anderson (ed.), Sociología de la familia, México, Fondo de Cultura Económica, pp. 116141.

Willmott, P. (1987): Friendship Networks and Social Support, Londres, Policy Studies Institute.

Wilson, E. O. (1980): Sobre la naturaleza humana, México, Fondo de Cultura Económica. 


\title{
RESUMEN
}

Los grupos de parentesco han tenido un papel relevante en las tareas de protección y asistencia tradicionalmente. Los cambios de nuestra sociedad inciden en el contenido y en la estructura de la familia. Algunos autores, apoyándose en el continuado descenso del tamaño de los hogares, el crecimiento de los hogares unipersonales, la presencia de la monoparentalidad, asociada a la soltería, sostienen la inevitable desmembración de las redes de parentesco y, consiguientemente, la desaparición de su función protectora. Frente a esta perspectiva se pretende mostrar la continuidad de los lazos de parentesco, a pesar de los cambios, y el mantenimiento de los rasgos característicos de la protección familiar: su configuración, sus fundamentos, límites y desafíos.

\begin{abstract}
Traditionally kinship groups have had a very important role in the tasks of protection and assistance. The changes in our society have affected the content and structure of families. That is why some authors, based on the continuous diminution of family size, the increasing number of unipersonal and monoparental families, hold out the disappearance of kinship nets, and therefore, the disappearance of their protective role. In opposition to this view, the author tries to show the continuity, in spite of these changes, of the kinship bonds, and the constancy, structure and fundaments, limits and challenges of a modern family protection.
\end{abstract}

